\title{
A transformação do espaço amazônico e seus reflexos na condição atual da cobertura e uso da terra
}

\section{The transformation of amazon space and its reflections on current condition of land use and land cover}

Maurício Silva - Mestre em engenharia civil pela Universidade Federal de Santa Catarina, 2007; pesquisador do INPE. E-mail: mauricio.silva@cra.inpe.br

Cláudia Pinheiro Nascimento - Doutoranda em Desenvolvimento Socioambiental pelo NAEA/UFPA; mestre em Geografia pela Universidade Federal de Rondônia. Doutoranda em Desenvolvimento Socioambiental pelo NAEA/UFPA. E-mail: nascimento.cp@gmail.com

Alexandre Camargo Coutinho - Doutora em Ciência Ambiental pela USP; pesquisador da EmbrapaCampinas.E-mail: alex@cnptia.embrapa.br

Cláudio Aparecido Almeida - Mestre em sensoriamento remoto pelo Instituto Nacional de Pesquisas Espaciais; pequisador do INPE. E-mail: claudio@dsr.inpe.br

Adriano Venturieri - Doutor em Geografia pela Universidade Estadual Paulista Júlio de Mesquita Filho (UNESP); pesquisador da Embrapa - Amazônia Oriental. E-mail: adriano@cpatu.embrapa.br.

Júlio César Dalla Mora Esquerdo - Pesquisador da Embrapa Informática Agropecuária; mestre em Agronomia pela Universidade de São Paulo e doutor em Engenharia Agrícola pela Universidade Estadual de Campinas. E-mail: julio@cnptia.embrapa.br

\section{Resumo}

A Amazônia, ao longo de sua história, passou por um intenso processo de transformação na sua forma e no seu conteúdo, fazendo com que diferentes elementos sociais, políticos e econômicos atuassem na transformação do seu espaço. Sendo assim, através da interpretação do atual uso e cobertura da terra, é possível verificar como os diferentes atores e políticas envolvidas se associaram em cada momento específico na história e atualmente refletem no espaço. Fazendo uso desta interpretação pretende-se abordar esses elementos e sua correspondente natureza transformada para buscar estabelecer os pontos de apoio nesta leitura para o processo de desflorestamento que a Amazônia sofreu nos últimos quarenta anos e no que estas áreas se transformaram.

\section{Palavras-chave}

Amazônia. Espaço. Desflorestamento. Uso da terra.

\begin{abstract}
Throughout its history, Amazonia has experienced an intense process of transformation in form and in content, involving different social, political and economic elements acting in the transformation of its space. Thus, through the interpretation of present-day land use and land cover, it is possible to verify how the different actors and politics involved were associated in each specific moment in history and how this is currently reflected in space. Making use of this interpretation, the intention here is to assess these elements and their corresponding transformations in nature in order to establish reference points for reading the process of deforestation that Amazonia suffered in the last forty years and under what conditions these areas were transformed.
\end{abstract}

\section{Keywords}

Amazon. Space. Deforestation. Land use. 


\section{INTRODUÇÃO}

O espaço amazônico, ao longo de sua história, passou por um intenso processo de transformações conjunturais e contextuais, envolvendo diferentes atores e políticas, que estiveram associados a interesses diferenciados, tanto na esfera local, quanto nacional e internacional.

O objetivo deste trabalho é apresentar como os diferentes elementos sociais, políticos e econômicos atuaram na transformação do espaço amazônico, principalmente a partir da implantação dos grandes projetos de infraestrutura e dos planos governamentais, da década de 1970 até os dias atuais. De forma mais específica, o trabalho pretende apresentar como os diferentes atores e políticas envolvidas se associaram em cada momento específico na história e como, atualmente, essas associações se refletem no espaço, através da interpretação do seu uso e cobertura.

Para uma melhor compreensão da condição do uso e cobertura da terra, a realidade amazônica foi tratada como um subsistema no interior do sistema espacial, que através do tempo foi tendo seus espaços naturais transformados em espaços produtivos, resultado de uma série de decisões e escolhas historicamente determinadas.

Buscando alcançar seu objetivo, o texto apresenta, além desta introdução e de considerações finais, outras quatro partes. A primeira aborda uma perspectiva histórica para o desflorestamento, seguida dos dados oriundos do programa de monitoramento do desflorestamento na Amazônia Legal. A terceira aborda as principais atividades relacionadas ao momento seguinte ao desflorestamento; e a quarta parte apresenta a situação mais recente do uso e cobertura da terra para estas áreas onde ocorreu o corte raso da vegetação e a substituição da cobertura florestal.

\section{PERSPECTIVA HISTÓRICADO DESMATAMENTO NAAMAZÔNIA}

A alteração territorial presenciada hoje na Amazônia resulta de mudanças que ocorreram na sociedade e na economia nas últimas décadas. Para o entendimento dessa alteração, é necessário compreender a interação entre processos locais e a dinâmica dos mercados globais (BECKER, 2007).

O ordenamento territorial da Amazônia reflete a visão e a ação de diferentes agentes que atuam de forma conjunta ou individualmente, interferindo diretamente no processo de formação socioespacial e nas atividades desenvolvidas na região. 
Castro (2007) analisa o ordenamento territorial da Amazônia a partir da racionalidade dos atores individuais e coletivos envolvidos e suas motivações na definição das estratégias socioespacias. Sendo assim, a perda da cobertura vegetal, seja em função da exploração madeireira, agropecuária ou mineração é reflexo da diversidade de lógicas e racionalidades que determinam as práticas sociais.

$\mathrm{Na}$ perspectiva de Fearnside (2005), foram as políticas de incentivos fiscais e subsídios governamentais os grandes indutores do desflorestamento da Amazônia, principalmente entre os anos de 1970 e 1980, assim como as políticas econômicas implantadas no Brasil.

Dentro de diferentes conceituais teóricos, a destruição das florestas tropicais tem sido prevista por organizações ambientais nacionais e internacionais (KOHLHEPP, 1992; FEARNSIDE, 1985; MAHAR, 1989; AB'SABER, 1989) e tem sido foco de discussões em níveis interno e externo. Atualmente, faz-se necessário entender a dinâmica do processo de desflorestamento, suas causas e consequências, no intuito de orientar as análises e ações governamentais para a definição de políticas que tenham o objetivo de promover a redução do desflorestamento e a melhor utilização das áreas desflorestadas.

O entendimento das transformações do espaço amazônico baseouse no conceito de formação socioespacial ${ }^{1}$ de Milton Santos (1982), no qual o espaço é considerado como uma realidade objetiva, um produto social e um subsistema da sociedade global; uma instância. Sua análise supõe a construção de uma epistemologia genética do espaço geográfico, fundada no fato de que as mudanças históricas conduzem a mudanças paralelas da organização do espaço (SANTOS, 1982, p. 51).

O processo de ocupação e desenvolvimento da bacia amazônica pode ser definido em três períodos distintos, conforme a associação entre o modo de produção dominante, as políticas implantadas para a incorporação da região e as políticas de desenvolvimento para a região.

A primeira fase de ocupação da região amazônica esteve associada, sobretudo, ao modo de produção extrativista, fazendo uso dos recursos florestais disponíveis, no qual predominou, principalmente, a retirada de matéria-prima. Apesar da dinâmica que esses produtos extrativistas incorporaram à região, seja através da implantação de infraestrutura ou mesmo pela efetivação de políticas

1 O conceito de formação Econômica Social e Espacial surge como uma nova forma de auxiliar a leitura e interpretação do espaço. Esta categoria diz respeito à evolução diferencial das sociedades, no seu quadro próprio e em relação às forças externas. A própria base para a explicação é a produção, o trabalho do homem para transformação, segundo leis historicamente determinadas. Dentro deste contexto, entram também as especificidades sociais, políticas e culturais que compuseram esse processo de formação espacial. 
governamentais, como foi o caso da extração do látex, a dinâmica de ocupação e desenvolvimento tinha, no modo de produção extrativista, o seu grande impulso (NASCIMENTO, 2009).

Neste primeiro momento, os índices de desflorestamento e destruição das florestas tropicais eram pequenos, associados a dinâmicas pontuais e que poucos impactos negativos trouxeram à região amazônica, principalmente por conta da forma como se estruturou a exploração dos recursos florestais com uso da mão de obra dos seringueiros. Vale ressaltar que neste período a principal atividade econômica fez uso da "floresta em pé".

Fearnside (2005, p. 113) afirma que "a floresta amazônica brasileira permaneceu intacta até o início da era moderna do desmatamento, que ocorreu com a construção da rodovia Transamazônica em 1970”.

Segundo Alves (2001), foi a partir da década de 1970 que o processo de ocupação da Amazônia acelerou-se e milhões de hectares de florestas foram derrubadas para a criação de pastos, projetos de colonização e reforma agrária.

A segunda fase do processo de ocupação da região amazônica está associada ao Golpe de Estado de 1964, e se estende até meados da década de 1980, caracterizando-se, sobretudo, pelas políticas governamentais de agregar e homogeneizar o território nacional, por meio da integração da Amazônia às demais regiões brasileiras (BECKER, 1998) através da construção de estradas, ligando o Centro-Sul à região Norte.

Este período foi marcado por um modelo desenvolvimentista e de integração, pautado por políticas de ocupação de cunho geopolítico, que foi concretizado através da implantação de grandes projetos de colonização e mineração. As políticas de incentivos fiscais, voltadas principalmente para os grandes projetos agropecuários também se fizeram presentes, viabilizando a transformação de áreas florestais em pastagens (FEARNSIDE, 1985; MAHAR, 1989; BECKER, 1998).

O marco inicial do processo de desflorestamento ocorreu, principalmente, entre as décadas de 1970 e 1980, quando os incentivos fiscais foram os principais indutores (MAHAR, 1978).

Fearnside (2005) associa o desflorestamento deste período à política econômica brasileira, marcada por um alto índice inflacionário. A terra era muito valorizada e seus preços atingiram níveis muito altos, que não justificavam seu uso como insumo para a produção agropecuária. A retirada da floresta possibilitava reivindicar a posse da terra e o desmatamento para a formação de pastagens era a forma mais barata e efetiva de sua utilização para a especulação (FEARNSIDE, 2005, p.114).

Novos Cadernos NAEA • v. 16 n. 1 • p. 229-248 • jun. 2013 
Segundo Margulis (2003), o processo de especulação da terra foi predominante até o ano de 1987, quando a produção bovina determinou o aumento do lucro das pastagens.

As contradições entre os programas governamentais de investimento em infraestrutura e os programas voltados à preservação ambiental marcam a terceira fase de ocupação da Amazônia, com início em meados da década de 1980 e persistência até os dias atuais.

O desflorestamento, segundo Fearnside (2005), pode ser analisado segundo um reflexo da economia nacional e apresenta os períodos de recessão e crescimento econômico brasileiro como um indicativo para a queda e o aumento dos índices de desflorestamento. Sendo assim, quanto maior o capital disponível na economia nacional, maior será o número de investimentos que demandam desflorestamento. Esta relação também se traduz para as políticas macroeconômicas anti-inflacionárias, que incluem políticas de restrição de gastos públicos e de subsídios agrícolas.

A recessão econômica brasileira é uma das formas de explicação para a queda das taxas de desflorestamento entre os anos de 1987 e 1991, período no qual os fazendeiros não tinham capacidade de expandir suas áreas desflorestadas e o governo não tinha recursos para a construção de rodovias e para implementar os projetos de assentamento. Outra explicação é o aumento das políticas públicas de combate ao desflorestamento na Amazônia, quando no ano de 1988 surgiu, por uma demanda da Secretaria Especial do Meio Ambiente e do IBAMA, em associação com o Ministério de Ciência e Tecnologia, o Programa de Monitoramento do Desmatamento das Formações Florestais da Amazônia Legal (PRODES), que, a partir de um levantamento sistemático, passou a estimar a taxa anual do desflorestamento e a extensão do desflorestamento bruto.

A partir de 1991 ocorre um aumento das taxas de desflorestamento, que alcança o seu ápice no ano de 1995, resultado do bom desempenho econômico obtido pelo Plano Real, iniciado em 1994.

A queda do desflorestamento em 2005 pode estar associada ao resultado desfavorável das taxas de câmbio para exportação, bem como à implantação de políticas mais efetivas contra o desflorestamento, implementadas pelo Ministério do Meio Ambiente, em associação com o IBAMA, no qual podemos citar o Programa de Ação para Prevenção e Controle do Desmatamento na Amazônia Legal (PPCDAM) e a elaboração do PRODES pelo Instituto Nacional de Pesquisas Espaciais (INPE), a partir de imagens de satélite, fato que aumentou a qualidade dos dados apresentados (FEARNSIDE, 2005). 
As políticas de combate ao desflorestamento a partir do ano de 2005, que envolvem as ações do PPCDAM, trouxeram uma queda substancial nas taxas. Neste momento, a teoria da associação entre a perda de cobertura vegetal e a economia, não se enquadra, pois, a partir de 2005, a economia nacional passa a alcançar melhores índices, refletida no aumento da taxa do Produto Interno Bruto (PIB) e o mesmo não ocorreu com as taxas de desmatamento.

Segundo o PRODES $(2010)^{2}$, o desflorestamento na Amazônia apresentou, a partir de 2005, um decréscimo significativo, partindo de 19 mil km² em 2005, para 7,4 mil em 2009. Esta queda ainda vem sendo verificada através dos dados prévios do levantamento para o ano de 2010, que apresentou uma estimativa de área desflorestada de 6,2 mil $\mathrm{km}^{2}$.

\section{HISTÓRICO DO DESFLORESTAMENTO}

O histórico de levantamentos anuais do PRODES viabilizou o acompanhamento da dinâmica e evolução do desflorestamento na Amazônia, do ano de 1988 ao ano de 2010 (Figura 1) e apoiou o desenvolvimento de análises para explicar seu comportamento ao longo deste período.

Figura 1: Dinâmica do desflorestamento na Amazônia Legal no período de 1988 a 2010 .

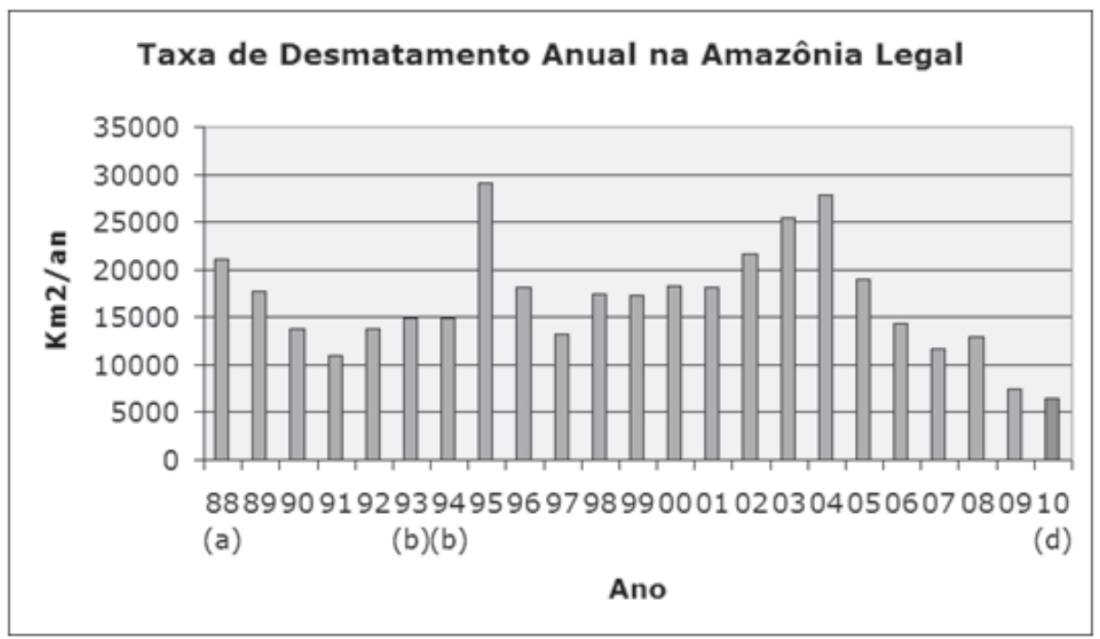

Fonte: <www.obt.inpe.br/prodes> (2010). Acesso em: abril 2011.

As taxas de desflorestamento anual, entre os anos de 1988 e 1991, apresentaram uma queda pontual ano a ano, provavelmente associada às políticas

2 Disponível em: <www.obt.inpe.br/prodes>

Novos Cadernos NAEA • v. 16 n. 1 • p. 229-248 • jun. 2013 
de comando e controle, implantadas para conter o processo de degradação. Neste período, as maiores concentrações do desflorestamento foram percebidas nos estados do Mato Grosso, Pará e Rondônia (Figura 2).

Figura 2: Evolução anual do desflorestamento nos estados da Amazônia Legal Brasileira no período entre 1988 e 2010.

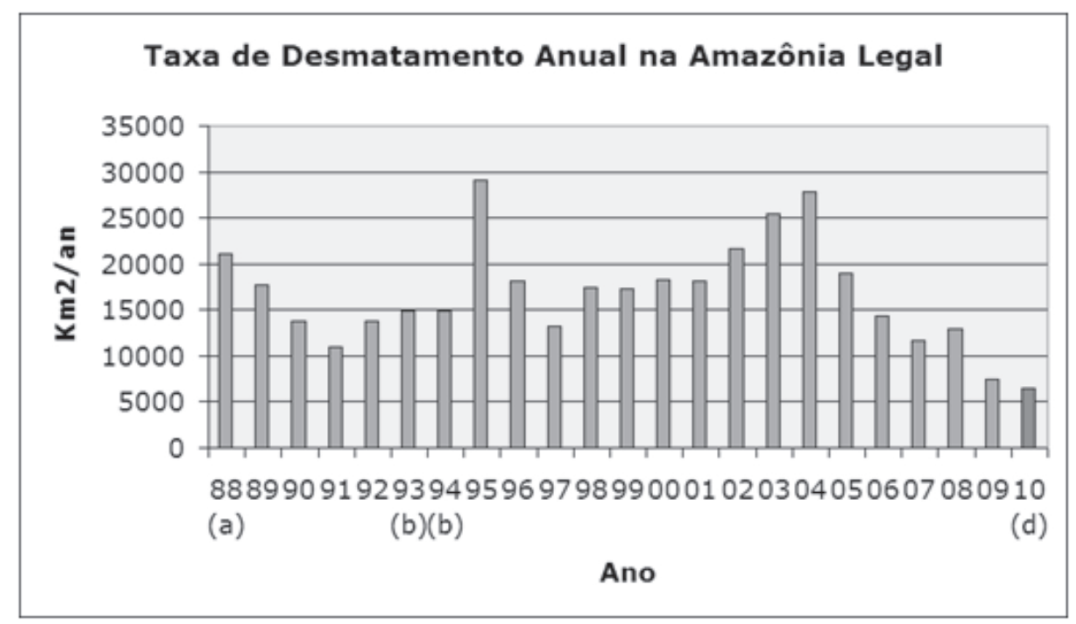

Fonte: <www.obt.inpe.br/prodes> (2010). Acesso em: abril 2011.

Uma análise das taxas anuais do desflorestamento entre 1991 e 1994, quando houve uma queda em relação aos anos anteriores, para os municípios da Amazônia Legal (ALVES et. al., 1998), demonstrou uma grande concentração de taxas nos municípios próximos à malha viária principal, nos flancos oriental, sul e sudoeste da Amazônia.

Segundo a análise de Alves (1999), no período de 1991-1996, 87\% dos desflorestamentos ocorreram dentro de $25 \mathrm{~km}$ de áreas de ocupação pioneira da rodovia, ou seja, às suas margens, mapeadas pelo trabalho de Tardin et al. (1979), enquanto cerca de $17 \%$ ocorreu entre os $25 \mathrm{~km}$ e $50 \mathrm{~km}$ do eixo Cuiabá-Porto Velho-Rio Branco, 33\% dentro de $50 \mathrm{~km}$ da malha viária ligando o Centro-Oeste a Santarém e a Transamazônica. Os dados demonstram que o desflorestamento teve seu processo incentivado ao longo dos eixos de desenvolvimento implantados na década de 1970, concentrando-se fortemente em regiões próximas às áreas de ocupação pioneira (ALVES, 1999).

As taxas de desflorestamento referentes aos anos de 1991-1995 representaram um diferencial quanto à possibilidade de estudo, uma vez que incluem a menor e a maior taxa da década e por apresentarem cobertura de nuvens relativamente moderada. Segundo Alves (2001), os resultados do trabalho demonstraram que a concentração do desflorestamento esteve associada ao 
longo dos eixos de desenvolvimento, com vários núcleos de taxas elevadas em regiões de polos de desenvolvimento (ALVES, 2001, p. 262).

Nesta mesma análise realizada por Alves (2001, p. 262), sobre o desflorestamento na Amazônia entre os períodos de 1991-1994, 1994-1997, e 1991-1997, ficou demonstrado que 90\% das taxas ocorreram dentro dos $100 \mathrm{~km}$ dos principais eixos de desenvolvimento, região correspondente às áreas destinadas aos projetos de colonização e polos de desenvolvimento, durante os anos de 1970 e 1980. Este mesmo trabalho detectou que as maiores taxas de desflorestamento ocorrem em áreas onde derrubadas maiores foram predominantes, e que as áreas desflorestadas tendem a se agrupar ao longo do tempo, formando clareiras cada vez maiores. A estimativa do trabalho foi de que áreas maiores que 50 ha e 200 ha corresponderam, respectivamente, a 74\% e 50\% da área desflorestada em 1991 1997. Desta forma, considerando o Código Florestal da época, que estabelecia uma reserva legal de $50 \%$ e a forma de apossamento instalada pelo INCRA, estes desmatamentos permitiam a geração de títulos com o dobro da área desmatada.

Segundo Margulis (2003), vários estudos referentes ao início da década de 1990 indicaram que os desflorestamentos se concentravam em poucas regiões, com $76 \%$ dos novos desflorestamentos ocorrendo em apenas 49 imagens do satélite Landsat, de um total de 229 para recobrir toda a Amazônia, a maioria ocupando o Arco do Desflorestamento. Em 1998, as áreas desflorestadas correspondiam a 76\% e concentravam-se nos estados do Pará, Mato Grosso e Rondônia, sendo que este percentual subiu para 85\% no ano de 2000 .

As taxas de desflorestamento, a partir do ano de 2000 até o ano de 2004, apresentaram um crescimento gradual até atingir seu pico no ano de 2004, dez anos depois da última grande taxa de desflorestamento. Este último grande pico alcançado pelas taxas de desflorestamento foi decisivo para a tomada de decisões pelo Governo Federal.

As políticas públicas implantadas nesse momento passaram a incluir políticas interministeriais conjuntas de combate ao desflorestamento, com foco no desenvolvimento sustentável, utilizando os conhecimentos das diferentes esferas de interesse dos ministérios como indicador das políticas ambientais.

Essa ação conjunta dos governos federal, estadual, municipal, juntamente com organizações não governamentais, organizações populares e movimentos de resistência, podem ser considerados os motivos da diminuição das taxas de desflorestamento. A partir do ano de 2005, as taxas diminuíram gradualmente e alcançaram seu menor índice no ano de 2010.

Muitos foram os avanços alcançados no Brasil no combate ao desflorestamento na Amazônia, contudo, a solução para o problema está mais 
bem delineada, mas ainda distante de ser alcançada, pois envolve questões relacionadas ao ordenamento territorial - um processo no qual diferentes interesses estão envolvidos, tanto na esfera pública quanto privada.

O maior desafio atual das questões referentes aos problemas ambientais na Amazônia encontra-se em reconhecer os interesses comuns que agem e vivem na Amazônia, tentando equilibrar as ações, no sentido de responder de forma igualitária a todos os interesses envolvidos, na busca de otimizar cada vez mais a utilização dos recursos naturais.

Uma melhor utilização das áreas desflorestadas também faz parte dos desafios para a Amazônia, pois, além de conter a expansão do desflorestamento, possibilitará uma melhor utilização das áreas com maior produtividade, através do uso de tecnologias mais avançadas e intensivas.

\section{TENTATIVAS PARA APONTAR AS CAUSAS DO DESFLORESTAMENTO}

Segundo Castro (2005), para o entendimento da dinâmica do desflorestamento, é importante associar a interpretação dos princípios da racionalidade econômica à análise das estratégias de caráter político dos agentes econômicos de espaços diferenciados da Amazônia.

Dentro desta perspectiva, é necessário levar em consideração quatro pontos fundamentais. Em primeiro lugar, não existe apenas uma causa do desflorestamento. Trata-se de múltiplas causas que dizem respeito à diferença da racionalidade de atores e de suas estratégias. Em segundo, essa alteração espacial está organicamente relacionada à estrutura social do país, desigual em renda e oportunidades. Em terceiro, há uma relação entre essas causas e a modalidade de inserção da Amazônia e do país na economia mundial globalizada. Finalmente, o último ponto diz respeito aos arranjos políticos e à disponibilidade de recursos naturais no território (CASTRO, 2005, p. 9).

A análise das causas do desflorestamento não pode dissociar a transformação do espaço e sua componente temporal. Neste sentido, o entendimento das dinâmicas criadas pelas políticas da década de 1960 e 1970, um modelo de desenvolvimento que não levava em consideração os impactos ambientais, apresenta componentes importantes para a análise das causas atuais do desflorestamento.

O processo estabelecido neste período de abertura da fronteira de recursos, com os programas de incentivo à colonização, à migração e à expansão pecuária, 
além de estarem diretamente associados ao desastre da perda de riquezas naturais, estabeleceram no imaginário coletivo a ideia de que os recursos são infindáveis, sem dono e que precisam ser tomados.

A dinâmica atual, presente no uso da terra e dos recursos naturais regionais na Amazônia, traz os traços tanto da inoperância e ineficiência dos programas governamentais, que não conseguiram fazer valer suas propostas, bem como das práticas criadas no imaginário coletivo da época.

Devemos considerar, também, os atores sociais e suas formas de atuação, sua capacidade econômica e articulação política, assim como os processos característicos de região de fronteira, como direito de propriedade, a ação do poder local e nacional, a dinâmica do processo e as motivações econômicas dos diversos atores envolvidos (CASTRO, 2005).

Segundo Castro (2005, p.14), a distinção do fenômeno de desflorestamento na fronteira amazônica, segundo uma classificação não sistemática, inclui três áreas de realidades distintas:

- O primeiro espaço corresponde à região que ficou conhecida como "Arco do Desmatamento", um conjunto de mais de 174 municípios (Pará, Mato Grosso e Rondônia) que somam as maiores taxas de desflorestamento;

- O segundo é denominado de "Fronteira Clássica", espaço marcado pelos programas de colonização dos anos de 1970 e 1980, e representa a estrutura padrão de ocupação da terra, na qual prevalece a pequena produção familiar, apesar de combinados com incentivos fiscais a médias e grandes empresas pecuárias e madeireiras (áreas ao longo das rodovias BR-230, BR-364, BR-010 e BR-163);

- O terceiro espaço é determinado pelo avanço de novas frentes nas atividades de pecuária e madeireira, mas já com abertura para monopólios de grãos, área articulada a partir do Mato Grosso, Goiás e Tocantins (franja sul do domínio de floresta tropical da Amazônia). É a região onde estão chegando os atores capitalizados, cujas estratégias e interesses estão vinculados à dinâmica da economia da pecuária e da soja.

\subsection{PECUÁRIA}

Embora exista uma discussão sobre os vários atores que contribuíram para o desflorestamento, a pecuária é apontada, por excelência, como a atividade responsável pela maior parte do desflorestamento (MARGULIS, 2003; ALENCAR et al., 2004; FEARNSIDE, 2005; CASTRO, 2005; COSTA, 2005).

O papel da pecuária no desflorestamento está associado, sobretudo, às crescentes extensões de terra por ela ocupadas, à padronização do uso da terra e 
à concentração fundiária por ela proporcionada, como estratégia de formação de estoques para o mercado futuro de terras (CASTRO, 2007).

A lucratividade é um dos fatores de peso na expansão da pecuária na Amazônia, em virtude da renda proporcionada pelas atividades que entram como fatores de complementaridade, como o caso das madeireiras, garimpos, comércio, pequena produção familiar, serviços e outras formas de extrativismo (FEARNSIDE, 2005; CASTRO, 2007).

A expansão da pecuária não está associada somente à disponibilidade de capital para investimento, mas associa-se, também, à expansão dos mercados internos e externos, à demanda por carne bovina no exterior e aos incentivos fiscais (ALENCAR et al., 2004).

A dinâmica da pecuária, neste caso, passa a seguir uma lógica, independentemente da imposta pelo mercado nacional, a possibilidade da supressão do espaço pelo tempo, em função da implantação do meio técnicocientífico internacional (SANTOS, 2006), contribui para que o mercado internacional e suas tendências atuem também nos mecanismos de organização da pecuária na região e, consequentemente, pela organização do espaço amazônico.

Margulis (2003) aponta a eliminação das barreiras sanitárias, com a erradicação da febre aftosa, o melhoramento das raças bovinas e das forragens, e a evolução da engenharia genética, como fatores que fazem da pecuária um investimento interessante, de baixo custo de produção, encarado como um meio de poupança e uma fonte segura de recursos monetários para os produtores.

A maior parte da expansão da pecuária ocorre em grandes propriedades, embora esta prática esteja sendo também disseminada em propriedades de pequenos agricultores que apresentam objetivos diferentes. Para os pequenos agricultores, o investimento na produção bovina ocorre como forma de diversificar a sua fonte de renda, com a adoção de sistemas de pecuária mista, com gado de corte e leite (CASTRO, 2005; COSTA, 2005).

Os grandes pecuaristas focam seu interesse na produção especializada e empresarial, com desenvolvido aparato tecnológico que o permite alcançar uma maior lucratividade (MERTENS et al., 2002).

Alencar et al. (2004) atribuem a expansão do rebanho bovino à rentabilidade da pecuária e à dinâmica expansiva dos mercados de carne, porém, apontam a complementaridade de outros fatores, tais como a especulação da terra e os créditos subsidiados, elementos necessários para o entendimento do processo de "pecuarização" da região. 


\subsection{ASSENTAMENTOS RURAIS E AGRICULTURA FAMILIAR}

Grande parte das áreas de pequena produção familiar tem ligação com o processo histórico de ocupação da região amazônica, quando o governo federal priorizou a criação de assentamentos rurais como válvula de escape para vários problemas sociais que se estruturavam em nível de Brasil. Esse processo foi normatizado pelo Instituto Nacional de Colonização e Reforma Agrária (INCRA), que continua a atuar nos dias atuais, criando assentamentos em locais isolados, desconsiderando as características naturais de aptidão agrícola, topografia e infraestrutura.

Existem várias estimativas sobre a contribuição das pequenas propriedades e dos pequenos agricultores para o desflorestamento da Amazônia. A mais antiga é uma contribuição de Fearnside (1993), baseada em dados do Instituto Brasileiro de Geografia e Estatística (IBGE), que indica uma taxa de 30\% do desflorestamento causado por esse grupo.

Estudos mais recentes, baseados no Censo Agropecuário do IBGE dos anos de 1995/1996 indicam que os proprietários de até 100 hectares, que é o tamanho padrão das propriedades para fins de colonização, são os responsáveis por 18\% do desflorestamento, porém, a contribuição da agricultura familiar para o desflorestamento pode variar dependendo da região analisada (ALENCAR et al., 2004).

Segundo Alencar et al. (2004), as contribuições da produção familiar para o desflorestamento variam principalmente em função da migração, de novos assentamentos e dos incentivos para a pequena produção agropecuária. A contribuição da economia nacional, neste caso, assume uma forma diferenciada, pois serve como forma de expropriação da mão de obra das cidades, quando as indústrias e o comércio não têm mais como absorver a força de trabalho expulsa do campo, em função da mecanização agrícola, resultando na volta de produtores familiares para o meio rural, aumentando a pressão pela terra, o que representa a criação de assentamentos emergenciais para suprir a demanda.

Costa (2004) defende que na contabilidade do desmatamento da Amazônia, que hoje se faz por taxa de desflorestamento bruto, as capoeiras - ou parte delas - seriam uma parcela de um "ativo ambiental” invisível, por serem áreas recuperadas ou em processo de recuperação ambiental, cujos valores não são levados em consideração, bem como estão ligadas às atividades de rotação de culturas e heterogeneidade de atividades em áreas predominantemente ligadas à agricultura familiar.

Novos Cadernos NAEA • v. 16 n. 1 • p. 229-248 • jun. 2013 
Essa ocupação desordenada em áreas pouco adequadas à agricultura, fruto de demandas emergenciais, associada ao baixo investimento de recursos financeiros e a precariedade de infraestrutura, especialmente da malha rodoviária, tem promovido altas taxas de transferência de títulos de propriedades e estimulando a assimilação das mesmas por grandes produtores, por meio de concentração fundiária, levando à abertura de novas frentes pioneiras de ocupação (COUTINHO, 2010, p.91).

\subsection{A INDÚSTRIA MADEIREIRA}

O aumento da atividade madeireira na região amazônica pode ser associado, dentro da realidade brasileira, à melhoria da infraestrutura que propiciou a exploração da madeira em terra firme, associado à mecanização de alta intensidade. Considerando ainda o cenário internacional, o declínio dos estoques de madeira no sudeste asiático contribuiu para o aumento da demanda internacional da madeira explorada na Amazônia (AMARAL, 1998).

Segundo Graça (2004), a exploração convencional da madeira, também denominada sem planejamento, ainda é a prática predominante nas áreas de atividades madeireiras na Amazônia e organiza-se dentro de um sistema complexo, aliando processos tradicionais aos modos mais agressivos de extração, com o uso de motosserras e adoção de processos industriais de beneficiamento primário da madeira.

Outro aspecto importante indicado por Graça (2006), que precisa ser observado em florestas não manejadas, é o retorno às áreas exploradas em intervalos curtos, para retirada de madeira de menor interesse econômico, até a exaustão completa dos recursos, muitas vezes levando ao corte raso da floresta.

A atividade madeireira está associada a vários tipos de impactos ambientais, tais como compactação e erosão dos solos, risco de extinção de espécies locais, aumento da suscetibilidade aos incêndios florestais e emissão de carbono para atmosfera. Estes impactos podem variar em função de fatores ligados ao manejo da floresta, tais como intensidade da exploração, planejamento da exploração, fatores físicos (topografia, solo e clima), fatores biológicos (estrutura e composição da floresta), entre outros (GRAÇA, 2006, p. 37).

Um grande problema associado à exploração convencional da madeira é a ocorrência dos incêndios florestais. Dependendo do grau de fragmentação da floresta e da intensidade da exploração madeireira, a vegetação fica mais suscetível ao fogo e acaba sendo atingida acidentalmente (ALENCAR et al., 2004). A extração da madeira cria um grande número de clareiras na floresta, 
abrindo o dossel para a penetração da luz, aumentando a quantidade de material combustível depositado no chão da floresta (NEPSTAD et. al., 2000).

Segundo Fearnside (2005, p.116), a extração da madeira aumenta a inflamabilidade da floresta, levando à queimada do sub-bosque, que coloca em movimento um ciclo vicioso de mortalidade de árvores, aumento da carga de combustíveis, reincidência do fogo e, consequentemente, a destruição da floresta. Esse processo, que se inicia de forma incipiente e não detectado como desflorestamento, vai progredindo e alcançando grandes extensões ao longo do tempo.

\subsection{O PAPEL DA PRODUÇÃO DE GRÃOS}

A crescente demanda pela produção de grãos na Amazônia, principalmente a de soja, tem sido apontada por diferentes autores como a causa mais recente do aumento das taxas de desflorestamento (CASTRO, 2007; FEARNSIDE, 2005; ALENCAR et. al., 2004; MARGULIS, 2003).

Para Coutinho (2010, p.93), a produção de grãos estabelece e mantém uma relação direta entre o mercado global de commodities agrícolas e as atividades desenvolvidas na fronteira do desflorestamento.

O mercado global para a soja é composto de três grandes ramificações: a soja a granel, o óleo de soja e o farelo de soja, sendo que a maior parte do farelo vai para a Europa alimentar porcos e aves, enquanto que a maior parte do óleo vai para a Ásia (FEARNSIDE, 2005).

O avanço da produção da soja tem sido associado ao estímulo para investimento do governo em infraestrutura, como hidrovias, ferrovias e rodovias, que permitem um melhor escoamento do produto. Outras formas de uso da terra, tal como as pastagens, não têm o peso político para induzir o governo na construção de infraestrutura.

Apesar da recente constatação da conversão direta de áreas de cobertura florestal natural em áreas de produção de grãos, sobretudo no estado de Mato Grosso (MORTON et al., 2006), a relação da produção de soja com o desflorestamento tem sido apresentada como uma relação indireta (ALENCAR et. al., 2004), pois a expansão da cultura tem acontecido de forma contínua em pastagens já ocupadas, onde o custo da implantação da atividade se torna menos dispendioso, denominado como "efeito de arrasto" (FEARNSIDE, 2005). Mas, por outro lado, a ocupação das pastagens faz surgir um novo problema, pois a soja acaba induzindo à expansão da atividade de pecuária para novas áreas de floresta (COSTA, 2000; FEARNSIDE, 2001, BECKER, 1998).

Novos Cadernos NAEA • v. 16 n. 1 • p. 229-248 • jun. 2013 


\section{A CONDIÇÃO ATUAL DO USO E OCUPAÇÃO DA TERRA}

Entre os anos de 2009 e 2011, o INPE desenvolveu um projeto, buscando estabelecer um novo ponto de partida para a leitura do que viria a cobrir as áreas desflorestadas na Amazônia através do projeto TerraClass (INPE; EMBRAPA, 2011). Este projeto buscou realizar o mapeamento em escala equivalente ao PRODES, do uso e da cobertura da terra para as áreas que, segundo o PRODES Digital, sofreram o corte raso da vegetação florestal existente. A área acumulada designada como desflorestada em vinte anos (1988-2008) perfaz uma superfície de cerca de 720 mil km², o que representa aproximadamente 17,8\% do domínio florestal da Amazônia.

Para as áreas desflorestadas, o projeto apresentou outras 11 classes de uso e cobertura da terra, que evidenciam as principais causas históricas do desmatamento, como: pasto limpo, pasto sujo, pasto com solo exposto e regeneração com pasto, todas as coberturas ${ }^{3}$ ligadas às atividades de pecuária. Vale ainda ressaltar que outras classes como vegetação secundária, agricultura anual e mosaico de ocupações também foram identificadas em diferentes proporções, evidenciando as áreas ligadas à agricultura familiar e agricultura de larga escala para produção de grãos.

Para as áreas ligadas à atividades de pecuária, o TerraClass apresentou (Tabela 1), para o ano de 2008, um total de $447 \mathrm{mil} \mathrm{km}^{2}$, cerca de $62 \%$ das áreas desflorestadas na Amazônia. Da mesma forma, o TerraClass apresentou um total de 150 mil km² de áreas cobertas por vegetação secundária, cerca de 35 mil km² de agricultura anual e 24 mil km² de uso por mosaico de ocupações, o que representa, respectivamente, $21 \%, 5 \%$ e 3,4\% das áreas desflorestadas.

Os demais 8,6\% são, na maioria, áreas com impedimento de mapeamento pela alta incidência de nuvens e demais classes, incluindo aí os 1,6\% de desflorestamento ocorrido em 2008.

Dessa forma, pode-se entender que a maior parte, do ponto de vista da extensão das áreas desflorestadas, está associada à atividade de pecuária (62\%) ou atividades que envolveram o abandono das atividades inicialmente atribuídas e encontram-se em um processo de regeneração da vegetação $(21 \%)$.

Cabe ressaltar, que dos 35 mil km², ou seja, 3,5 milhões de hectares, 3 milhões encontram-se no estado do Mato Grosso, principal estado produtor de grãos da Amazônia. Esses 35 mil km² representam cerca de 5\% do uso das

\footnotetext{
3 A principal diferença entre as diferentes classes de pasto está ligada à cobertura por espécies herbáceas, que quanto maior for esta cobertura, melhor a condição de produção para a pecuária.
} 
áreas desflorestadas, porém, tomando-se apenas o estado do Mato Grosso e seu desflorestamento acumulado, as áreas de agricultura anual cobrem 15\% do total, ou seja, três vezes mais do que o número comparativo para toda a Amazônia.

Outro aspecto relevante é que as áreas definidas pelo projeto como mosaico de ocupações, que envolvem principalmente áreas de projeto de assentamento com lotes menores, estão bem distribuídas nos estados da Amazônia, variando entre 5\% a 10\%, mas que em números absolutos, dos 24 mil km², cerca de 11 mil estão no estado do Pará.

Tabela 1: Áreas de uso e cobertura da terra mapeadas pelo projeto TerraClass, referentes ao ano de 2008 .

\begin{tabular}{l|r|r}
\hline \multicolumn{1}{c|}{ Classe } & Área $\left(\mathbf{k m}^{2}\right)$ & \multicolumn{1}{c}{$\mathbf{\%}$} \\
\hline Pasto Limpo & $335.714,94$ & $46,7 \%$ \\
\hline Pasto Sujo & $62.823,75$ & $8,7 \%$ \\
\hline Regeneração com Pasto & $48.027,37$ & $6,7 \%$ \\
\hline Pasto com Solo Exposto & 594,19 & $0,1 \%$ \\
\hline$\ldots$ Pastagens ... & $\mathbf{4 4 7 . 1 6 0 , 2 5}$ & $\mathbf{6 2 , 2} \%$ \\
\hline Vegetação Secundária & $150.815,31$ & $21,0 \%$ \\
\hline Agricultura Anual & $34.927,24$ & $4,9 \%$ \\
\hline Mosaico de Ocupações & $24.416,57$ & $3,4 \%$ \\
\hline Demais Classes & $61.891,62$ & $8,5 \%$ \\
\hline Total & $\mathbf{7 1 9 . 2 1 0 , 9 9}$ & $\mathbf{1 0 0 , 0 \%}$ \\
\hline
\end{tabular}

Fonte: INPE e Embrapa (2011).

\section{CONSIDERAÇÕES FINAIS}

A transformação do espaço amazônico esteve relacionada, ao longo do seu processo de formação socioespacial, a diferentes elementos e atores, que em cada período específico se associaram de forma diferenciada, dando origem a realidades e contextos distintos.

A exuberância das riquezas naturais existentes na Amazônia foram, desde o início do seu processo de ocupação, determinantes para a ocorrência desse processo na região. Em cada momento histórico, interesses diferenciados eram atendidos, todos associados ao modo de produção dominante e à divisão internacional do trabalho.

Sendo assim, a Amazônia apresenta períodos distintos na organização do 
seu espaço, possíveis de serem diferenciados, em função dos interesses atendidos, que ora vinculavam-se ao mercado internacional e, em outros momentos, ao mercado nacional. Foram os modos de produção da economia capitalista que influenciaram, em grande parte, o estilo de desenvolvimento do Brasil e da região amazônica.

A associação dos interesses econômicos, juntamente com a construção do imaginário coletivo, que Castro (2010) denomina de "Mito do Eldorado", foram os elementos que permitiram a materialização no espaço das formas de ocupação e transformação da realidade amazônica.

Este processo intensificou-se a partir da década de 1970, com as políticas de investimento em grandes obras de infraestrutura e de desenvolvimento regional, mas esteve presente desde o início da ocupação da região, com a exploração das drogas do sertão e do látex, mesmo que com menores custos ambientais.

O atual quadro de distribuição do uso e da cobertura da terra reflete as políticas implantadas na região e corrobora na explicação de uma pecuarização da região, visto a grande quantidade de áreas cobertas por formas distintas de pasto, cerca de $62 \%$. Ainda se pode perceber que a ótica do desmatamento como forma de obter acesso à terra tem sua explicação na grande quantidade de áreas abertas e posteriormente abandonadas. Cerca de 21\% do total das terras abertas encontram-se em processo de regeneração da vegetação.

O processo de formação socioespacial da Amazônia apresentou uma distribuição de áreas concentradas nas atividades ligadas à pecuária, mas também apresentam uma concentração de atividades agrícolas de larga escala de produção agrícola, com culturas de ciclo anual, no estado do Mato Grosso, ou seja, na borda sul do Arco do Desmatamento.

O quadro atual do uso e cobertura da terra na Amazônia demonstra como o espaço atual é reflexo das ações políticas e econômicas do passado, quando a pecuária se apresentou como a principal atividade desenvolvida nas áreas desflorestadas da Amazônia, demonstrando que passados quarenta anos, o espaço amazônico é hoje a materialização das ações do passado, induzindo na forma como o desenvolvimento para a região tem sido pensado.

\section{REFERÊNCIAS}

AB'SABER, A.N. Zoneamento ecológico e econômico da Amazônia. Questões de escala e método. Estudos Avançados, São Paulo, v. 3, n. 5, p.4-20, maio/ago. 1989. 
ALENCAR, A.; NEPSTAD, D.C.; McGRATH, D.; MOUTINHO, P.; PACHECO, P.; DIAZ M del C.V.; SOARES-FILHO, B. Desmatamento na Amazônia: indo além da emergência crônica. Belém: Instituto de Pesquisa Ambiental da Amazônia, 2004. 87 p.

ALVES, D. S. et. al. Análise da distribuição espacial das taxas de desflorestamento dos municípios da Amazônia Legal no período de 19911994. São José dos Campos: Instituto Nacional de Pesquisas Espaciais, 1998. (INPE-AMZ-R04/98).

ALVES, D. S. An analysis of the geographical patterns of deforestation in Brazilian Amazonia in the 1991-1996 period. In: WOOD, C. H.; PORRO, R. (Eds.). Land use and deforestation in the Amazon. Gainesville: University Press of Florida, 1999.

O processo de desmatamento na Amazônia. Parcerias Estratégias, Brasília, v.12, n. 1, p. 259-275, set. 2001.

AMARAL, P. Manejo florestal comunitário. Relatório da primeira oficina de manejo florestal comunitário. Porto Dias: WWF/SUNNY/CTA, 1998. 41p.

BECKER, B. K. Amazônia. São Paulo: Ática, 1998. p.112.

BECKER, B. K. A Amazônia e a política ambiental brasileira. pp. 22-40 In: SANTOS, M,BECKER, B. K. (orgs.) Território, territórios: ensaios sobre o ordenamento territorial. Rio de Janeiro: Lamparina, 2007.

CASTRO, E. Dinâmica socioeconômica e desmatamento na Amazônia. Novos cadernos do NAEA, Belém, v. 8, n.2, p. 5-40, 2005.

Políticas de ordenamento territorial, desmatamento e dinâmicas de fronteira. Novos cadernos do NAEA, Belém, v.10, n.2, p. 105-126, 2007.

COSTA, F. A. Questão Agrária e macropolíticas para a Amazônia. Estudos Avançados, São Paulo, v. 19, n. 53, p. 131-156, 2005.

COSTA, F. A. PATH dependency e a transformação agrária do bioma amazônico: o sentido econômico das capoeiras para o desenvolvimento sustentável. Novos cadernos do NAEA, Belém, v. 7, n.2, 2004.

COUTINHO, A.C. Queimadas: fenômeno complexo determinado por conjunturas distintas. Revista de Política Agrícola, Brasília, v. 19, n. 4, p. 7894, 2010. 
FEARNSIDE, P.M. 1985. Environmental change and deforestation in the Brazilian Amazon. pp. 7089 In: J. Hemming (ed.) Change in the Amazon Basin: Man's Impact on Forests and Rivers. Manchester University Press, Manchester, U.K

Deforestation in Brazilian Amazônia: the effect of population and land tenure. Ambio, v. 22, n. 8. p. 537-545, 1993.

O cultivo da soja: como ameaça pra o meio ambiente na Amazônia Brasileira. In: SIMPÓSIO INTERNACIONAL AMAZÔNIA 500 ANOS. O V Centenário e o Novo Milênio: lições de história e reflexões para uma nova era. 2002. Belém. Anais... Belém: MPEG; UFPA/FCMB, 2002. 55 p.

Desmatamento na Amazônia brasileira: história, índices e conseqüências. Megadiversidade, Belo Horizonte, v. 1, n. 1, p. 113-123, 2005.

GRAÇA, P. M. L. A. Monitoramento e caracterização de áreas submetidas à exploração florestal na Amazônia por técnicas de detecção de mudanças. 2004. 275f. Tese (Doutorado em Sensoriamento Remoto) - Instituto Nacional de Pesquisas Espaciais, São José dos Campos, 2004. Disponível em: <http:// urlib.net/sid.inpe.br/jeferson/2005/02.15.16.02>. Acesso em: 20 abr. 2011.

INPE-INSTITUTO NACIONAL DE PESQUISAS ESPACIAIS. Sistema de Detecção do Desmatamento em tempo real na Amazônia - DETER: Aspectos Gerais, metodológicos e Planos de desenvolvimento. Disponível em: <http://www.obt.inpe.br/deter/metodologia_v2.pdf>. Acesso em: 5 abr. 2011.

Monitoramento da cobertura florestal da Amazônia por satélites. Disponível em: <http://www.obt.inpe.br/deter/avaliacao/ RelatorioMonitoramento.pdf>. Acesso em: 5 de abr. 2011.

INPE; EMBRAPA. Mapeamento de uso e cobertura da terra nas áreas desflorestadas da Amazônia Legal brasileira. Disponível em: <http:/ /www. inpe.br/cra/terraclass>. Acesso em: 29 ago. 2011.

KOHLHEPP, G. Desenvolvimento regional adaptado: o caso da Amazônia brasileira. Estudos Avançados, São Paulo, v. 6, n. 16, p. 81-102, 1992

MAHAR, D.J. Desenvolvimento econômico da Amazônia: uma analise das políticas governamentais. Rio de Janeiro: IPEA, 1978. 259p

Government Policies and Deforestation in Brazil's Amazon Region. Washington: Word Bank Publication, 1989. 
MARGULIS, S. Causas do desmatamento da Amazônia Brasileira. Brasília: Banco Mundial, 2003. 100p.

MERTENS, B.; POCCARD-CHAPUIS, R.; PIKETTY, M.-G.; LACQUES, A.-E.; VENTURIERI, A. Crossing spatial analyses and livestock economics to understand deforestation processes in the Brazilian Amazon: the case of Sao Felix in South Para. Agricultural Economics, v. 27, n. 3, p. 269-294, 2002.

MORTON, D.C.; DEFRIES, R.S.; SHIMABUKURO, Y.E.; ANDERSON, L.O.; ARAI, E.; ESPIRITO-SANTO, F.del B.; FREITAS, R.; MORISETTE, J. Cropland expansion changes deforestation dynamics in the southern Brazilian Amazon.Proceedings of the National Academy of Sciences of the United States of America - PNAS. v.103, n.39, p. 14637-14641, 2006.

NASCIMENTO, C. P. Cenários da produção espacial urbana de Porto Velho. 2009. Dissertação (Mestrado em Geografia) - Fundação Universidade Federal de Rondônia, Porto Velho, 2009.

NEPSTAD, D.; CAPOBIANCO, J.P.; BARROS, A.C.; CARVALHO, G.; MOUTINHO, P.; LOPES, U.; LEFEBVRE, P. Avança Brasil: os custos ambientais para a Amazônia. Belém: Alves, 2000. 24p.

PRODES. Programa de Monitoramento do Desmatamento das Formações Florestais da Amazônia Legal. Ano base 2010.Disponível em: http://www.obt.inpe. br/prodes Acesso em: 26 de abril de 2011.

SANTOS, M. Espaço e sociedade. 2. ed. Rio de Janeiro: Vozes, 1982.

A natureza do espaço: técnica e tempo, razão e emoção. 4. ed. São Paulo: EDUSP, 2006. ( Coleção Milton Santos).

TARDIN, A.T.; SANTOS, A.P.; LEE, D.C.L.; MAIA, F.C.S.; MENDONÇA, F.J.; ASSUNÇÃO, G.V.; RODRIGUES, J.E.; ABDON, M.M.; NOVAES, R.A.; CHEN, S.C.; DUARTE,V.; SHIMABUKURO, Y.E. Levantamento de áreas de desmatamento na Amazônia Legal através de imagens do Satélite LANDSAT. São José dos Campos: INPE, 1979. 142p. 